\title{
Using Information Processing Theory to Teach Social Stratification to Pre-Service Teachers
}

\author{
Jennifer L. Brown ${ }^{1}$ \\ ${ }^{1}$ College of Education and Health Professions, Columbus State University, Columbus, Georgia, USA \\ Correspondence: Jennifer L. Brown, Department of Teacher Education, Columbus State University, 4225 \\ University Avenue, Columbus, USA. Georgia. E-mail: brown_jennifer2@columbusstate.edu
}

Received: July28, 2014

Accepted: August 30, $2015 \quad$ Online Published: September 29, 2015

doi:10.5539/jel.v4n4p19

URL: http://dx.doi.org/10.5539/jel.v4n4p19

\begin{abstract}
Information in context has meaning for the student, easily understood, easily retrieved, and successfully moves to long term memory. If information is not in context, rote memorization occurs with the less meaningful information, and information is not easily retrieved or successfully stored in long term memory. The purpose of this study was to determine if using a teaching simulation to teach social stratification can improve the students' knowledge of culture and knowledge of effective instructional practices using 21 incoming freshman students. This study used a mixed methods approach with journal entries and inventories. The results indicated the pre-service teachers felt the simulation allowed them to apply the classroom content within a direct learning experience.
\end{abstract}

Keywords: classroom simulation, information processing theory, pre-service teachers, social stratification

\section{Introduction}

\subsection{Theoretical Framework}

Atkinson and Shiffrin (1968) first described the information processing theory as a cognitive theory of learning that describes the processing, storage, and retrieval of knowledge in the mind. Basically, it is the systematic way that we learn. The student is like a computer because he or she inputs information, saves it, and outputs the information.

In the information processing theory, there are three phases: Sensory Memory, Working Memory, and Long-term Memory. First, the environmental stimuli (i.e., sights, sounds, tastes, smells, and feelings) enter the Sensory Memory, where it is transformed into information. The Sensory Memory has a very large capacity but a very short duration. There are two roadblocks for information moving into Working Memory, perception and attention. Perception is the process of detecting stimuli and giving it meaning. Attention enables the student to select or ignore stimuli. Both of these roadblocks are major issues in today's classroom. The presentation of material that integrates kinesthetic and tactual cues, such as a teaching simulation, can assist with attention. The teacher should gain the students' attention with interest and maintain it throughout the learning process (Slavin, 2012).

Next, if those obstacles did not hinder it, the information moves into Working Memory. Working Memory is a place where the stimuli or information is temporarily stored and where calculations and transformations occur. The capacity is seven plus or minus two new pieces of information, and the duration of the information is 5 to 20 seconds. The contents include words, images, ideas, and/or sentences. To oversee this process, the central executive supervises attention, makes plans, retrieves information, and integrates it. When working with information in the Working Memory, organization and rehearsal can improve the chances of information moving to long-term storage because the student gains more meaning for the information and it encodes it into the long-term memory. A teaching simulation provides a meaningful and active rehearsal activity for the student to move the information into long-term memory. By providing frequent distributed practice, the students can retrieve and utilize previously learned content (Slavin, 2012).

Lastly, if the information processing is not impeded by inference or decay, the final stage is Long-term Memory, where the information is stored permanently. The capacity and duration are practically unlimited. The contents include propositional networks, schemata, productions, episodes, and images. Within Long-term Memory, there 
are two types of memory: Explicit and Implicit. Explicit memory is the conscious recall of general knowledge or episodes. Implicit memory is the unconscious recall, such as classical conditioning and procedural memory. A teaching simulation or learning episode within the classroom would be explicit memory. Proper encoding of information through the simulation results in it being accurately and quickly retrieved from the Long-term Memory for use. For example, rote memorization has little meaning to the student. It is retrieved less easily and less frequently compared to information that has meaning and is understood (Slavin, 2012).

\subsection{Classroom Instruction}

One possible way for the pre-service teachers to transform the gained knowledge and attitudes into practice may be incorporation of teaching simulations into the post-secondary classroom. Often, post-secondary instructors use lecture methods to deliver content; however, active learning, such as classroom simulation, allow the students to become involved with the content in a meaningful way (e.g., Chambers, 2010; Chickering \& Gamsen, 1987; Pascarella et al., 2004; Tamim et al., 2011). Typically, simulations are utilized with the training of airline pilots and medical professionals (e.g., doctors and nurses) (De Jong, Lane, \& Sharp, 2012). Moreover, simulations are used often in sociology courses to demonstrate various social issues, such as social stratification (e.g., Coghlan \& Huggins, 2004). Presnilla-Espada (2014) found role-play simulations with clear guidelines and instructor guidance allow pre-service teachers to prepare for the various situations that they will encounter within their future classrooms. Despite the documented effectiveness of this experiential learning, the current literature, which examines non-virtual simulations within teacher education, is limited (e.g., Cruikshank, 1969).

Dorn (1989) defines teaching simulations as a game with multiple players who operate within an explicit set of rules. To achieve the goal of the game or simulation, the players participate in role playing activities, which require peer interactions. Successful achievement of the goal depends on strategic planning and decision making, which are devised by the players. According to Dorn (1989), these teaching simulations can provide a direct learning experience that can increase student motivation and the likelihood of gaining and maintaining the student's attention. This direct learning experience can also provide insights into an unseen world for the students, especially those pre-service teachers with backgrounds different from their future classroom students. In addition, the pre-service teachers can apply the knowledge gained from the Information Processing Theory (Atkinson \& Shiffrin, 1968) into a real world setting. They will be able to see the benefits of active learning versus passive learning through lecturing, for example. Furthermore, the simulation allows the student to connect theory and practice (De Jong et al., 2012).

\subsection{Purpose of the Study}

The purpose of this study was to determine if using a simulation to teach social stratification could improve college students' knowledge of culture and knowledge of effective instructional practices.

\section{Methods}

\subsection{Research Design}

The research design for this study was an exploratory mixed methods design. Within this design, the qualitative data collection and results built upon with a follow-up quantitative data collection and analysis (Creswell, 2007). This design allowed the researcher to determine the impact and the effectiveness of the Classified Monopoly Teaching Simulation on pre-service teachers within an introductory diversity course.

\subsection{Participants}

The college of education is part of a four-year institution in the southeastern United States that is considered a master's level school. Enrollment at the state university has increased over the past 5 years and has reached a maximum of 8,307 in the fall of 2011. The participants included 23 members of an introductory diversity course, which was held during the fall semester. The goal of this course was to prepare pre-service teachers for teaching culturally diverse students in the P-12 setting. This diversity course was a required program component for all education majors within the College. The participants included traditional-aged freshmen who have declared majors with the College (i.e., Early Childhood Education, Fine Arts Education, Physical Education, Secondary Education, and Special Education). Of the 21 participants, 4 (19.0\%) students were males, and 17 (81.0\%) students were females. Regarding racial classification, 11 (52.4\%) students were white, and 10 (47.6\%) students were black.

\subsection{Intervention}

Based on a modified monopoly game designed for cadets at US Military Academy at West Point by Morten Ender (2004), Classified Monopoly Teaching Simulation began with each participant randomly drawing an 
assignment card from the course instructor to determine which social class he or she was born into. At each Monopoly ${ }^{\circledR}$ game board, there were eight players. Of the eight players, two were upper class, two were upper middle class, two were lower-middle class, and two were working class. Each social class had specific rules and procedures. To begin the game, the upper class received $\$ 2000$ in cash and two inherited properties, the upper middle class received $\$ 1500$ in cash and on inherited property, the lower middle class received $\$ 1000$, and the working class received $\$ 500$ in cash. The movement rules varied by social class. For example, the upper middle class could decide whether to move the sum of the numbers shown on the dice or plus one. The working class could only move the sum of the numbers shown on the dice. Each social class had limits on the types of property that they could purchase, except upper class, who could purchase all properties. Weekly salaries and procedures for getting out of jail varied by social class. The game ended when two players declared bankruptcy and retired from the game. The winner was determined based on the amount of cash and property on hand at the end of the game. All other Monopoly ${ }^{\circledR}$ game rules applied.

\subsection{Data Collection}

Journal Entries. At the end of class, the participants completed a journal entry to reflect upon what they learned through the simulation and offer suggestions for improving the game's rules and/or implementation. Each of the journal entries was read by the researcher, and emerging themes were identified.

Measure. The participants were administered a pretest at the beginning of the semester and a posttest at the end of the 16-week semester. The measure used for the pre- and posttest was the Inventory of Cross-Cultural Sensitivity (Cushner, 1986), which was developed by Dr. Kenneth Cushner at Kent State University. The purpose of this measure was for the participants to self-assess their intercultural experiences. As a participant in the diversity course, it was hoped that the level of sensitivity would increase over time as a result of the content and learning experiences presented throughout the course. The total score ranged from 32 to 224 . The measure had 32 items, which were subdivided into five subscales: Cultural Integration, Behavioral, Intellectual Interaction, Attitude Toward Others, and Empathy.

- Cultural Integration Scale assessed the extent an individual incorporates elements from other cultures into his or her daily activities.

- Behavioral Scale assessed the extent an individual adapts his or her behavior or the level of comfort when interacting with others.

- Intellectual Interaction Scale assessed the extent an individual searches for knowledge from other cultural viewpoints.

- Attitude Toward Others Scale assessed an individual's attitude toward others.

- Empathy Scale assessed the extent an individual identifies with the feelings of others.

For each statement, the participants were asked to select a number that best corresponds to their level of agreement with each statement. The response scale ranged from 1 to 7 with 1 being Strongly Disagree and 7 being Strongly Agree. Reliability analyses were conducted to determine if the measure was internally consistent. The alpha coefficient for the pretest was .77, and the alpha coefficient for the posttest was .56. The low posttest alpha coefficient was contributed to the lack of variation in participants' responses. The measure was deemed to be internally reliability based on a criterion of .50 and greater for the alpha coefficient.

\section{Results}

\subsection{Journal Entries}

A series of descriptive analyses were conducted on the participants' final assets at the end of the simulation. There were six participants classified as working class, five participants classified as lower middle class, four participants classified as upper middle class, and six participants classified as upper class. The mean assets ranged from $\$ 296.50$ to $\$ 2,371.83$. The means and standard deviations increased by social class. Table 1 presents the minimum, maximum, mean, standard deviation, and average gain or loss for the final assets by class level. The majority of the participants remained within the financial ranges of their initially assigned class. Of the 21 participants, only two participants (i.e., one lower middle class and one upper middle class) gained enough assets to move up in social class. The only social class to lose assets was the working class. 
Table 1. Descriptive statistics for the final assets by class

\begin{tabular}{cccccc}
\hline Class & Min. & Max. & M & SD & Gain/Loss \\
\hline Working & $\$ 131.00$ & $\$ 422.00$ & $\$ 296.50$ & $\$ 107.43$ & $<\$ 203.50>$ \\
Lower Middle & $\$ 850.00$ & $\$ 2150.00$ & $\$ 1311.20$ & $\$ 523.14$ & $\$ 311.20$ \\
Upper Middle & $\$ 1463.00$ & $\$ 2197.00$ & $\$ 1736.50$ & $\$ 318.81$ & $\$ 96.50$ \\
Upper & $\$ 1529.00$ & $\$ 3354.00$ & $\$ 2371.83$ & $\$ 597.55$ & $\$ 21.83$ \\
\hline
\end{tabular}

Seven of the participants stated they were surprised by their amount of assets at the end of the game. Student A who was a member of the working class responded, "I really thought that ... I was going to be able to work my way up." Student B who was a member of the upper middle class responded that her social class presented her with "more opportunities than some of the other players". On the other hand, Student $\mathrm{C}$ who was a member of the working class claimed "bad luck when it came to dice rolling", and both Students D, lower middle class, and E, working class, claimed bad investments (e.g., property purchases) impacted their final assets. Student F, who was a member of the upper class, stated her social class "helped me have the confidence to purchase more property without worry". From an observational standpoint, the researcher was surprised by two notable occurrences. First, there were several participants, who were traditional-aged freshmen, had never played the game of Monopoly. Second, more than half of the participants did not read the directions prior to beginning the game despite the instructor stating that procedure. Those participants who read the directions were more familiar with the possible options to increase their assets (e.g., property auditions and the process for getting out of jail). Based on the evidence, these participants learned a valuable lesson of social stratification; it is difficult to gain enough assets to move beyond the social class that one was born into. As pre-service teachers, it is essential that they learn this lesson so they can become better equipped with tools to assist their future students with overcoming such obstacles.

\subsection{Measure}

A series of paired $t$-test was conducted to determine if there was a statistically significant change from the preand posttest within the scale scores. For the Cultural Integration Scale, there was a statistically significant increase from the pre-test to the posttest, $t(22)=2.21 ; p=.038$. The mean pre-test score was 35.30 with a standard deviation of 10.33, and the mean posttest score was 38.04 with a standard deviation of 9.58 . For the Behavioral $[t(22)=0.87 ; p=.393]$, Intellectual Interaction $[t(22)=-0.71 ; p=.484]$, Attitude Toward Others $[t(22)=-0.53 ; p=.601]$, and Empathy Scales $[t(22)=1.08 ; p=.294]$, there was not a significant change from pre-test to posttest. The means for these scales were nearly unchanged. Table 2 presents the means and standard deviations for each scale by measure.

Table 2. Means and standard deviations for each scale by measure

\begin{tabular}{ccccc}
\hline & \multicolumn{2}{c}{ Pre-test } & \multicolumn{2}{c}{ Posttest } \\
Scale & $M$ & $S D$ & $M$ & $S D$ \\
\hline Cultural Integration & 35.30 & 10.33 & 38.04 & 9.58 \\
Behavioral & 30.87 & 2.85 & 31.39 & 3.31 \\
Intellectual Interaction & 30.87 & 5.01 & 30.30 & 5.00 \\
Attitude Toward Others & 28.17 & 3.76 & 27.83 & 3.35 \\
Empathy & 25.61 & 3.26 & 26.39 & 3.82 \\
\hline Total & 150.83 & 18.07 & 153.96 & 14.45 \\
\hline
\end{tabular}




\section{Discussion}

Since the majority of the teachers in today's classrooms tend to have homogenous backgrounds, it is essential for pre-service teachers to experience how to integrate different cultural elements into the classroom. In addition to providing a student-centered learning in activity, these teaching simulations allow post-secondary instructors to model appropriate and effective instructional methods. The pre-service teachers can see the application of a specific theory or concept (e.g., information processing theory) instead of just reading about it in a book or hearing a lecture during class. In turn, this exposure to such methods would increase the likelihood of implementation into the P-12 classroom; therefore, their future students can benefit from the years of educational research. Thus, the theory can be put into practice.

There were some limitations to this study. First, the study was conducted with one class of incoming freshman students. Further research could examine the effectiveness of the stimulation with other students (e.g., sophomore, junior, senior, or graduate students). Second, the Classified Monopoly Simulation was one of many hands-on activities during a 16-week semester. It is difficult to determine if the difference from pre- to posttest with the Cultural Integration Scale can be contributed to the Classified Monopoly Simulation.

\section{References}

Atkinson, R. C., \& Shiffrin, R. M. (1968). Human memory: A proposed system and its control processes. In K. W. Spence, \& J. T. Spence (Eds.), The psychology of learning and motivation (Vol. 2, pp. 89-195). New York: Academic Press. http://dx.doi.org/10.1016/S0079-7421(08)60422-3

Chambers, T. (2010). What I hear you saying is... : Analysis of student comments from the NSSE. College Student Journal, 44(1), 3-24.

Chickering, A. W., \& Gamson, Z. F. (1987). Seven principles for good practice. AAHE Bulletin, 39, 3-7.

Coghlan, C. L., \& Huggins, D. W. (2004). "That's not fair!”: A simulation exercise in social stratification and structural inequality. Teaching Sociology, 32(2), 177-187. http://dx.doi.org/10.1177/0092055X0403200203

Creswell, J. W. (2007). Educational research: Planning, conducting, and evaluating quantitative and qualitative research (3rd ed.). Upper Saddle River, NJ: Prentice Hall.

Cruickshank, D. R. (1969). The use of simulation in teacher education: A developing phenomenon. Journal of Teacher Education, 20(1), 23-26. http://dx.doi.org/10.1177/002248716902000105

Cushner, K. (1986). The inventory of cross-cultural sensitivity. Kent, OH: School of Education, Kent State University.

De Jong, T., Lane, J., \& Sharp, S. (2012). The efficacy of simulation as a pedagogy in facilitating pre-service teachers' learning about emotional self-regulation and its relevance to the teaching profession. Australia Journal of Teacher Education, 37(3), 34-43. http://dx.doi.org/10.14221/ajte.2012v37n3.6

Dorn, D. S. (1989). Simulation games: One more tool on the pedagogical shelf. Teaching Sociology, 17, 1-18. http://dx.doi.org/10.2307/1317920

Ender, M. G. (2004). Modified monopoly: Experiencing social class inequality. Academic Exchange Quarterly, $8(2), 249-253$.

Pascarella, E. T., Wolniak, G. C., Cruce, T. M., \& Blaich, C. F. (2004). Do liberal arts colleges really foster good practices in undergraduate education? Journal of College Student Development, 45(1), 57-74. http://dx.doi.org/10.1353/csd.2004.0013

Presnilla-Espada, J. (2014). An exploratory study on simulated teaching as experienced by education students. Universal Journal of Educational Research, 2(1), 51-63.

Slavin, R. E. (2012). Educational psychology: Theory and practice (10th ed.). Boston, MA: Pearson Education.

Tamim, R. M., Lowerison, G., Schmid, R. F., Bernard, R. M., \& Abrami, P. C. (2011). A mult-year investigation of the relationship between pedagogy, computer use and course effectiveness in postsecondary education. Journal of Computing in Higher Education, 23, 1-14. http://dx.doi.org/10.1007/s12528-010-9041-4 


\section{Copyrights}

Copyright for this article is retained by the author(s), with first publication rights granted to the journal.

This is an open-access article distributed under the terms and conditions of the Creative Commons Attribution license (http://creativecommons.org/licenses/by/3.0/). 